\title{
Collaboration on accelerators
}

\section{The US administration's backing for the newest accelerator will encourage high-energy physicists; it should also prompt them to ask what happens next in their relations with their colleagues elsewhere.}

Not every day of the week, in these times, is there news of the construction of a new particle accelerator, which is one reason why last week's announcement that the US administration will throw its weight behind the Superconducting SuperCollider (SSC) is memorable. It is easy to forget how much time has passed since the high-energy physics community began working for the proposal five years ago. And although some may prefer to use the word "lobbying", that would unfairly slight the way an awareness of costs has forced on high-energy physics an untraditional sense of responsibility.

Given the measured pace at which these projects are now designed and then financed, it could even be that SSC will be the most powerful accelerator to be put into service before this century is over. With luck, it may be working by, say, 1993, but that will not leave time for the accelerator next in line to be designed in the United States and then built before the end of the 1990s. European accelerator builders will also have their hands full until 1993 or thereabouts with the project to convert the magnet of the electronaccelerator LEP (not yet in service) to a superconducting magnet. The Soviet Union seems not to be in a mood for joining the competition at this stage, although that could change.

SSC is more than just another accelerator, both as an emblem of something and for what it will, or may, accomplish. In round numbers, it will increase by two orders of magnitude the mass of the particles that may be created artificially above that of the heavy bosons mediating the weak interaction, the $\mathrm{Z}$ and $\mathrm{W} \pm$ particles produced at Geneva, at the CERN highenergy physics laboratory, in the past two years.

On this occasion, moreover, there is more to say that the usual "so what?". At least to outsiders, particle physics is in a curious condition, littered with undiscovered particles. The undiscovered object called the Higgs particle is a continuing offence against the successful electroweak theory that accounts for the weak nuclear force, mediated by the $\mathrm{Z}$ and the $\mathrm{W} \pm$; no doubt the theoreticians are right to say that they have no idea what the mass should be, and therefore have no cause, as yet, to be downcast about their theory, but it must surely allow their imaginations to go begging for a foundation while this particle is missing.
The same (or similar) people seem to have learned to live more easily with the lack of a top quark, one of the ingredients of hadronic (strongly interacting) matter believed essential just a few years ago. The lack (so far) of a magnetic monopole and the failure (so far) to show that even protons decay, both inferences from the Grand Unified Theories fashionable early in this decade, matter less to people's pride now that attention has turned to radically different kinds of theories. In short, there are a few immediate questions that should be answered quickly when SSC is operating, but the list is not so long that the experimental programme will be determined in advance for several years.

None of this should be surprising. If one adds to the length of time taken to build a big new accelerator that required to plan it and then to win government support, the half-life for building a machine is lengthening while that of a fashionable theory is, on the average, more or less what it has always been - less than a decade, but not much less. On the face of things, if that were how events are determined, the case for building the next accelerator would be stronger with each succeeding generation. But theoreticians do learn from experiments, with the result that the two timescales are in reality tied together, which is why the strongest case for building the next accelerator is always that it will help to make theoreticians' imaginations function in a well-grounded fashion. Others, vicariously perhaps, are also enlivened in the process.

The High-Energy Physics Advisory Panel (HEPAP), advisory to the US Department of Energy, will naturally avoid notions as vague as these when seeking to justify the concepts to the US Congress. But, in reality, these forms of words may not be as inept as they seem. Why not let the Congress sense, just for once, that an essential part of the process of asking meaningful questions about the way that matter is constructed, together with the laws of nature that go with matter, is the stimulation of some factual conundrum?

Two other questions will arise in the months ahead, of which one (in this year of competitiveness) will be that of the commercial benefits to be won from building SSC; HEPAP has a sound record of telling the truth whenever possible, but on this occasion it will also be able to boast of planning to build the largest cryogenic facility (or some word like that) on the face of the Earth, not to mention the world's most powerful accelerator. Adding up the field energy of the world's helium-cooled superconducting magnets installed in diagnostic NMR machines would not tell quite the same tale.

The more durable case for SSC is that it is technically as clever an advance on its predecessors as are most technically advanced products. SSC may not (as yet) have the cleverness of the CERN technique for making protons and antiprotons circulate in the same ring, but that or its like could yet emerge. Meanwhile, with the intention is to circulate bunches of protons in opposite directions in separate vacuum tubes within the poles of the same superconducting niobium magnets in such a way that the circulating frequency exactly matches that of the increasing magnetic field throughout a whole cycle of operation. Can that count for nothing with the US Congress? And it will surely count for something that it will take as long for ordinary mortals to walk around the instrument as they can walk, with ordinary discomfort, in a day.

The more teasing question will be that of international collaboration. The US Congress will want to know when the burden it is now asked to carry will be assumed by other legislatures' taxpayers. Whatever the number turns out to be several thousands of millions of dollars is a lot of money. For the time being, the US Department of Energy has chosen to pin the Stars and Stripes on SSC, inviting cooperation from those elsewhere who may have a few tens of millions to spend for the sake of understanding, but who want nothing in return.

HEPAP should give some thought to this perplexing question. Many of its members' closest colleagues are people who work elsewhere, many of whom have interesting things to say about the best way to go next. Naturally, given that all accelerators have some chauvinistic attributes, experimentalists are constrained in what they can accomplish.

But everybody's interest is that highenergy physics should be made international, as in a curious way it is already: a person with a good idea or, better still the design of a good experiment, will be welcome anywhere. Why not institutionalize him (or her) by asking for an extra 0.1 per cent to found a data centre, next century's ivory tower, that keeps this interesting subject on its toes?

John Maddox 